\title{
The status quo's role in improving the estimation of willingness to pay in choice experiments
}

\author{
Alexandru MAXIMำ, Teodora ROMAN²
}

\begin{abstract}
:
European household consumers have seen a gradual increase in the cost of their electricity bill, partly due to ambitious support policies for the development of renewable energy. Some consumers may have a higher willingness to pay (WTP) for clean energy, which could constitute a competitive advantage for electricity suppliers branding themselves as "sustainable".

A discrete choice experiment has been used in order to estimate the WTP of households for renewable energy. For the last decade, researchers have debated whether to add a "status quo" / "not willing to pay for changes" option in the experimental design, as this may generate complications and not add sufficient benefits.

In this paper we use an original approach based on two parallel model estimations applied to the same sample of respondents in order to demonstrate the effect of adding a "status quo" option. Our results show that not including it would have led to an overestimation of about one third of the respondents' WTP.

While more research on the topic is needed, we demonstrate the risk of simplifying the experimental design and propose a facile method of enhancing the experiment with a dual model design.
\end{abstract}

Keywords: discrete choice experiment, status quo, renewable energy, household consumers, willingness to pay

\section{Introduction}

Global efforts to limit the progress of climate change have been primarily focused on limiting the output of greenhouse gasses from anthropic activities. Out of such activities, the sectors of transportation and energy have seen significant progress in the path towards sustainability, being two of the largest producers of greenhouse gasses. The development of alternative transportation solutions (especially in urban areas) and the rapid growth and development of renewable energy, respectively have helped mitigate the issue of emissions from such activities.

As part of this process, renewable electricity has seen a steady year on year growth across the globe, with a compound annual growth ratio of $15 \%$ in non-hydroelectric "green" electricity over the last 15 years. In absolute terms, production of such energy is currently highest in Asia \& Oceania, followed closely by Europe, with North America in a rather distant third place (Energy Information Administration, 2019).

Such progress has been fundamentally supported by various governmental policies that encouraged private investment in renewable energy (RE) production facilities, such as green certificate and feed-in tariff schemes, both of which have seen widespread use throughout European Union (EU) member states. One of the downsides of these programs from the perspective of household consumers has been an increased pressure on electricity prices. This, combined with the liberalization of electricity markets, as 
demonstrated by Fiorio \& Florio (2013), has led to increased energy costs, amplifying the latent issue of energy poverty Bouzarovski et al., 2012). The many benefits of developing renewable energy production (such as energy security, environmental protection, and economic development) are primarily observable at a general societal level, while payment for such benefits is requested at the individual household level.

Under these circumstances, several researchers have sought to assess the willingness to pay (WTP) of consumers for green energy. One of the most widely acknowledged methods for measuring WTP, especially in the case of non-tangible benefits (such as public goods, environmental protection and health services) is the discrete choice experiment (DCE). This method simulates a purchasing experience, in which sets of two or more different offerings with varying prices are provided to respondents who can then opt for one, thus helping identify their WTP for each benefit included in the offering.

One of the issues debated among specialists has been whether the experimental design should include the so-called "opt out" or the "status quo" option, which involves refusing all offerings, similar to walking out of a store without making a purchase. While there are valid arguments for both including and excluding this element from the experiment, we believe that the benefits of the "status quo" option (SQ) outweigh its disadvantages.

The aim of this paper is to provide empirical evidence that demonstrates the risks of not including the SQ in a DCE and to demonstrate how it could be easily implemented, reducing or eliminating some of the disadvantages discussed in the existing literature. This is achieved through a DCE that assesses the WTP of household electricity consumers in Romania for the benefits of RE, which includes the SQ option. The research results provide a relevant contribution to the debate regarding this methodological design issue and the approach demonstrates how the SQ can be implemented seamlessly and with a reduced negative impact on the results of a study.

The paper is structured in five sections. Beyond the introduction, section 2 provides a bibliographical context for the research, presenting some of the opposing points of view regarding the use of SQ. Section 3 provides a brief overview of the methodology. Section 4 illustrates the results of the study and demonstrates the negative impact of excluding the SQ from the experimental design. Finally, section 5 presents the overall conclusions and discusses some of the implications of our results.

\section{Research context and literature review}

The SQ offers respondents an option of deciding not to express their intention of purchasing one of the offerings presented to them in a DCE choice set. There are two approaches that are considered to be similar - 'status quo' (the respondent chooses to remain with their current alternative to the offers being made) and 'opt out' (the respondent chooses not to purchase any of the offerings, without specifying what their alternative is). Pedersen and Gyrd-Hansen (2013) discuss the differences between these alternatives in more detail and provide observations regarding common misuses of both options by researchers in various fields. 
Literature regarding the use of SQ in DCEs provides empirical arguments both in favour and against its usefulness. Indeed, most studies that we have been able to analyse have not expressed a specific recommendation against the use of SQ, but they do present a phenomenon called 'status quo bias' or 'status quo effect'. This means that, when confronted with a choice between a set of options (each with its own cost), as well as maintaining their status quo (at no additional cost), some respondents will have a specific preference to opt for the status quo.

Research has identified several reasons for which this phenomenon manifests itself. Tinelli et al. (2016) state that in DCE studies in the area of medical services there seems to be a relatively higher preference for services that respondents have experienced (i.e. status quo) compared to others that are being proposed as alternative offerings. Bonnichsen and Ladenburg (2015) also find strong evidence of SQ bias in the medical field and conclude that this is caused by payment based protest attitudes. Oehlmann et al. (2017) assess the situation from the perspective of environmental studies and conclude that SQ bias is inversely correlated with the number of alternatives in a choice set, suggesting that respondents will choose the SQ if their specific preferences in terms of offerings are not matched. The authors also identify several other factors that seem to amplify the SQ bias: high similarity among the alternative offerings, a high number of choice tasks and a wider range of attribute levels - all of which tend to increase the difficulty of the choice tasks, similar to the findings of Haaijer et al. (2001). Finally, the authors also conclude that the respondents' awareness of the environmental situation also affects SQ preference and that a choice between two hypothetical options and a status quo alternative may increase the propensity to choose the SQ option.

The study of Chen et al. (2017) points out the fact that some segments of the respondent sample may have a specific preference for the status quo or for specific attributes due to factors such as gender, citizenship or environmental activism. Such heterogeneity of preferences can be methodologically mitigated through econometric procedures, but, as is the case for our own study regarding renewable energy, the underlying societal issues need to be taken into consideration before imposing a standard cost on the whole population. Finally, Sandorf et al. (2016) find evidence that DCE surveys administered over the internet may lead to a higher than average preference for the SQ option.

Issues such as the ones presented above have determined some researchers to consider whether the inclusion of the SQ option is indeed sufficiently useful. Norhidayah et al. (2019) provide some evidence to support the idea that including the SQ option does not generate significant changes in WTP measurement or in the quality of the model. In fact, some researchers, such as Kaenzig et al. (2013) have opted to completely exclude the SQ option from their research due to the estimation difficulties that can arise from the issues listed above.

Fundamentally, the exclusion of the SQ option is incorrect from a theoretical and practical standpoint. By not including an opt-out or status quo alternative, the respondents will be required to choose an offering for which, in reality, they would not be willing to pay - a "forced choice" as exemplified by Pedersen and Gyrd-Hansen (2013). Thus, the resulting model would likely overestimate the WTP of consumers. In addition, some researchers, such as Grabicki and Menges (2017) provide evidence showing that DCEs are not always affected by SQ bias. 
Furthermore, some studies have proposed measures that could help mitigate SQ issues. Ahtiainen et al. (2015) demonstrate the use of respondent specific definitions of the status quo. Barreiro-Hurle et al. (2018) perform a meta-analysis of DCE studies and conclude that accounting for heterogeneity of responses, excluding protest responses and easing the choice's cognitive burden reduce the presence of SQ bias. These findings are consistent with those found in some of the other studies referenced above. Bonnichsen and Ladenburg (2015) seem to successfully mitigate SQ bias caused by payment based protest responses by first presenting respondents with an 'entreaty', providing justifications for the pricing, thus attempting to generate a state of empathy and understanding. Based on the findings of Oehlmann et al. (2017), SQ bias can also be attenuated by easing the effort necessary for respondents to make the choices (e.g. higher dissimilarity among alternatives, fewer choice sets) and, in the case of environmental studies, making sure that the respondents are well aware of the current environmental situation.

\section{Methodology}

We believe that a better implementation of the SQ response option is preferable to its outright exclusion. For this reason we have sought to incorporate the status quo alternative in our experimental design while attempting to limit its potential negative impact on the WTP and model estimation.

The study used to illustrate and test the proposed approach of incorporating the SQ is a DCE that seeks to estimate the WTP of Romanian households for renewable electricity. The DCE method is based on the Random Utility Theory, which is used to study choice behavior. This states that consumers make choices based on a latent construct called "utility", which is composed of a visible, measurable component and a random component, as illustrated in Equation 1. Consumers are asked to choose one of several profiles or offerings (product, service etc.) characterized by a set of attributes with specific levels. The grouping of such profiles is called a choice set and the theory states that a person is likely to choose the profile which they deem to have the greatest utility.

$$
U_{i n}=V_{i n}+\varepsilon_{i n}=a_{i}+\beta_{1} x_{1 i}+\beta_{2} x_{2 i}+\ldots+\beta_{k} x_{k i}+\varepsilon_{i n}
$$

where:

$U_{\text {in }}$ - latent utility associated by person $\mathrm{n}$ to choice profile $\mathrm{i}$;

$V_{i n}$ - systemic and measurable component of the utility associated by person $\mathrm{n}$ to choice profile $\mathrm{i}$; $\varepsilon_{i n}$ - random component of utility associated by person $\mathrm{n}$ to profile $\mathrm{i}$;

$\mathrm{x}_{\mathrm{kn}}$ - the level of attribute $\mathrm{k}$ in choice profile $\mathrm{i}$.

In order to estimate the probability of respondents choosing a specific profile, an assumption needs to be made regarding the distribution of the random component $\left(\varepsilon_{i n}\right)$. In this study we have chosen to assume a logistical distribution, thus using conditional multinomial logistic regression model to estimate probabilities of choosing a specific profile $\left(P_{i n}\right)$, as demonstrated in Equation 2. 
$P_{i n}=\Pi_{i n}=\frac{\exp \left[U_{i n}\right)}{\sum_{j=1}^{n} \exp \left(V_{i n}\right)}=\frac{e^{\alpha i+\beta 1 x 1 i+\beta 2 x 2 i+\ldots+\beta k x k i}}{\sum_{j=1}^{n} e^{\alpha j+\beta 1 x 1 j+\beta 2 x 2 j+\ldots+\beta k x k j}}$

(2)

The WTP can then be calculated for each attribute using the formula in Equation 3.

$W T P=-\frac{\beta_{\text {attribute }}}{\beta_{\text {cost }}}$

where $\beta$ are the coefficients in the logistical regression equation.

The experimental design is a $4^{5}$ balanced main effects design with a fractional orthogonal set of profiles. This means that we used five attributes with four levels each to define the profiles in the choice sets. We used the "shifting" method to define 16 choice sets, as exemplified in Table 2 (consisting of two profiles and the status quo option), which were designed so as to avoid dominated sets (with obviously advantageous choices) and any overlapping of the attribute levels between the two profiles of the choice set.

Table 1. Definition of attributes and levels

\begin{tabular}{|l|l|l|l|l|}
\hline Attributes & Level 1 & Level 2 & Level 3 & Level 4 \\
\hline Added cost to the monthly electricity bill & 0.9 EUR & 3.3 EUR & 5.5 EUR & 10 EUR \\
National level of energy independence & $75 \%$ & $90 \%$ & $85 \%$ & $80 \%$ \\
$\begin{array}{l}\text { New jobs created at the county level } \\
\text { Reduction of pollution effects focal rural }\end{array}$ & 3 & 10 & 15 & 20 \\
$\begin{array}{l}\text { Additional funds for loca } \\
\text { development }\end{array}$ & $10 \%$ & $20 \%$ & $30 \%$ & $40 \%$ \\
\hline
\end{tabular}

Table 1 illustrates the attributes and levels used in the experimental design. A more detailed explanation of how these levels and attributes were chosen is provided in Maxim (2015).

The manner in which the choice set incorporates the SQ option is similar to the approach presented by Veldwijk et al. (2014). We first present the options (e.g. Offer A and B), asking the respondents to choose the one that they prefer. Immediately after this choice is made, we ask them to state which option they would choose if they would need to sign the contract today (Offer A, B or the status quo). In this manner we can observe the choices made by the same sample of respondents first through a forced choice (no SQ option) and then with an unforced choice. This approach was expected to allow us to verify the presence of the SQ bias, without compromising the WTP estimation.

Table 2. Example of a choice set and accompanying questions

\begin{tabular}{|l|l|l|l|}
\hline & Offer A & Offer B & Status quo \\
\hline Added cost to the monthly electricity bill & 3.3 EUR & 5.5 EUR & 0 EUR \\
National level of energy independence & $85 \%$ & $75 \%$ & $70 \%$ \\
New jobs created at the county level & 15 & 10 & 0 \\
Reduction of pollution effects & $30 \%$ & $20 \%$ & $0 \%$ \\
Additional funds for local rural development & $1 \%$ & $2 \%$ & $0 \%$ \\
\hline Out of A and B, I prefer: & $\square$ & $\square$ & \\
If I were to sign today, I would choose: & $\square$ & $\square$ & $\square$ \\
\hline
\end{tabular}

Table 2 provides an example of a choice set within the DCE. The 16 choice sets were presented along with a questionnaire that allowed us to monitor additional variables, such as socio-demographic and lifestyle traits of the respondents. The survey 
and DCE were administered to a sample of 188 households that own their home in Iaşi County in Romania, resulting in a total of 3008 choices being recorded.

With regard to the sampling procedure, the initial target population of the study included the 8.5 million homeowners who are contractual household consumers of electricity in Romania. However, the limited scope of the study only allowed us to focus on those located within the area of Iaşi County (which represent approximately $4 \%$ of the entire population). Additionally, electricity supply contracts are recorded separately for each dwelling, regardless if the holder is also the registered 'consumer' at another location (as would be the case for owners of several dwellings). As a result, given that no publicly available list of household electricity consumers exists, a sampling frame could not be established, thus making any attempt at a probabilistic sampling unfeasible. The resulting methodological approach was a judgemental sampling procedure, as defined by Malhotra \& Birks (2008), attempting to create a sample with similar socio-demographic traits as the overall population. After filtering out non-homeowners and incomplete questionnaires, we obtained a sample of 188 homeowners, which is skewed towards more educated respondents (sample median education - Bachelor; population median education level - high school). However, the sample does resemble the population in terms of age and gender. The median age of the respondents is 39 (35-39 is the median age interval at the population level) and $47 \%$ of the respondents were women $(50 \%$ in the total population) (Data.gov.ro, 2019).

With regard to the sample size, Orme (2009) provides guidelines on the number of observations needed in order to successfully produce a choice experiment model, based on Sawtooth Software's experience in implementing such studies. This depends on the number of choice tasks per respondent and the number of levels used in the experimental design. Our sample size exceeds the recommended value by $50 \%$, partly due to the relatively high number of choice tasks per respondent.

While both the sampling procedure and sample size do generate some limitations, explained in the conclusions, these do not hinder the study from meeting its overall goal. The results of the study are presented in the following section.

\section{Results}

After analyzing the data collected during the implementation of the DCE we were able to calculate the following regression coefficients:

Table 3. Results of the DCE analysis, including SQ option

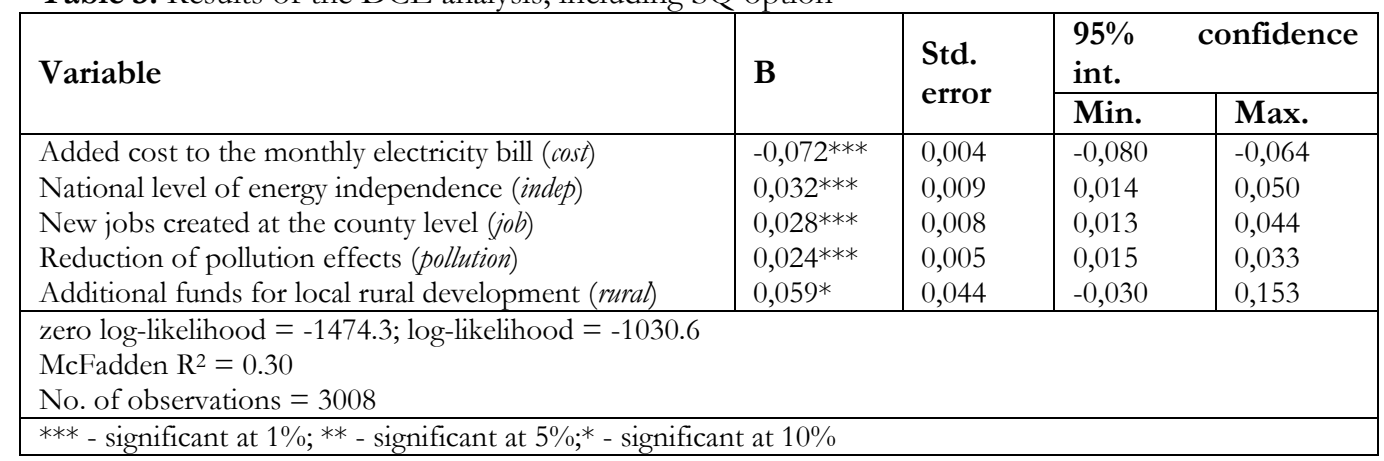


As seen in Table 3, all five attributes have a significant contribution to the utility of the profiles, thus affecting the choices made by consumers. The sign of the coefficients is in line with the economic theory: benefits that contribute to welfare have positive signs and the cost has a negative sign. The rural attribute has a rather low level of significance, as well as a wide confidence interval. Thus, it cannot be conclusively stated that the "Additional funds for local rural development" has a clear contribution to utility. The McFadden $\mathrm{R}^{2}$ value was calculated according to the indications of Greenacre (2013) and the value of 0.3 shows that the model has a good chance of accurately predicting the choices of households with regard to renewable electricity offerings (Louviere et al., 2000).

In order to assess whether the respondents may have been affected by the SQ bias, we verified the frequency with which the SQ option was selected. Out of the total of 3008 observation, the status quo was chosen a total of 881 times $(29.3 \%$ of cases). This result cannot confirm the existence of SQ bias, although in a significant number of cases neither of the two offers were chosen by the respondents. The result is generally below the average of studies that have demonstrated SQ bias in the medical field, such as Bonnichsen \& Ladenburg (2010) or in the environmental field, as exemplified by Oehlmann et al. (2017).

Based on the data presented in Table 3 and the formula of Equation 3, the marginal WTP of consumers for each attribute can be calculated. This refers to the amount of money households would be willing to pay for each $1 \%$ or 1 unit increase in the attribute levels. The conditional multinomial logistic regression model can then be used to calculate the overall utility of specific profiles or offers. In turn, these values can be used to calculate the "compensating variation" - the amount of money that needs to be paid or received in order for a household to maintain the same level of welfare after a change appears in the existing offer (Holmes \& Adamowicz, 2003). The compensating variation can be calculated based on the formula in Equation 4.

$C v=\left(1 / \beta_{\text {cost }}\right)\left(V^{1}-V^{0}\right)$

where

$V^{\wp}$ - the systemic component of the utility associated with the status quo

$V^{A}$ - the systemic component of the utility associated with the new offer

Table 4. WTP of households for various RE impact scenarios (EUR)

\begin{tabular}{|c|c|c|c|c|c|c|c|c|}
\hline & $\mathbf{U}_{\max }$ & $\mathbf{U}_{\min }$ & Independence & Jobs & Pollution & Rural & Average $_{1}$ & Average $_{2}$ \\
\hline indep & $90 \%$ & $75 \%$ & $90 \%$ & $75 \%$ & $75 \%$ & $75 \%$ & $80 \%$ & $80 \%$ \\
\hline jobs & 20 & 3 & 3 & 20 & 3 & 3 & 10 & 15 \\
\hline pollution & $40 \%$ & $10 \%$ & $10 \%$ & $10 \%$ & $40 \%$ & $10 \%$ & $30 \%$ & $20 \%$ \\
\hline rural & $4 \%$ & $1 \%$ & $1 \%$ & $1 \%$ & $1 \%$ & $4 \%$ & $2 \%$ & $3 \%$ \\
\hline WTP/month & 7.1 & 1.6 & 3.0 & 3.0 & 3.8 & 2.2 & 4.3 & 4.1 \\
\hline WTP/year & 85.0 & 19.3 & 36,1 & 35.8 & 45.0 & 25.9 & 51.1 & 49.5 \\
\hline
\end{tabular}

Table 4 illustrates the monthly and yearly WTP of households for various scenarios that could result from the benefits of developing the RE sector. The $U_{\max }$ and $U_{\text {min }}$ scenarios show the WTP for the maximum and minimum levels of improvement used for each of the attributes respectively. The Independence, Jobs, Pollution and Rural scenarios assign the highest level for the corresponding attributes and the lowest level for each of the remaining three. The two Average scenarios show two plausible average 
increases in the attribute values and illustrate the corresponding WTP of households. One limitation of the conditional multinomial logit model is that the WTP values are assumed to be homogeneous across the entire sample, while in reality we expect some variations among different market segments.

In order to demonstrate the effect of excluding the SQ option from the experimental design, we decided to provide an estimation of the model based on the responses to the first question (the forced choice between Offers A and B). The results are presented in Table 5.

Table 5. Results of the DCE analysis, excluding SQ option

\begin{tabular}{|c|c|c|c|c|}
\hline \multirow{2}{*}{ Variable } & \multirow{2}{*}{ B } & \multirow{2}{*}{$\begin{array}{l}\text { Std. } \\
\text { error }\end{array}$} & \multicolumn{2}{|c|}{$95 \%$ confidence int. } \\
\hline & & & Min. & Max. \\
\hline Added cost to the monthly electricity bill $(\cos t)$ & $-0,062 * * *$ & 0,003 & $-0,069$ & $-0,056$ \\
\hline National level of energy independence (indep) & $0,030 * * *$ & 0,006 & 0,016 & 0,046 \\
\hline New jobs created at the county level $(j o b)$ & $0,032 * * *$ & 0,006 & 0,020 & 0,047 \\
\hline Reduction of pollution effects (pollution) & $0,028^{* * *}$ & 0,004 & 0,022 & 0,037 \\
\hline Additional funds for local rural development (rural) & $0,077 * * *$ & 0,037 & $-0,004$ & 0,153 \\
\hline \multicolumn{5}{|l|}{$\begin{array}{l}\text { zero log-likelihood }=-2085.0 ; \text { log-likelihood }=-1567.7 \\
\text { McFadden } R^{2}=0.25 \\
\text { No. of observations }=3008\end{array}$} \\
\hline
\end{tabular}

The model estimation does not seem to change significantly, although the effective exclusion of the SQ from the choice set seems to have reduced the predictive power of the model, reducing the $\mathrm{McFadden} \mathrm{R}^{2}$ to 0.25 . In addition, the rural attribute is now also significant at the $1 \%$ level. In order to provide a functional comparison to the results of the SQ model, we will use the same formula to recalculate the data presented in Table 4 using the new model.

Table 6. WTP of households for various RE impact scenarios - forced choice (EUR)

\begin{tabular}{|l|l|l|l|l|l|l|l|l|}
\hline & $\mathbf{U}_{\max }$ & $\mathbf{U}_{\min }$ & Independence & Jobs & Pollution & Rural & Average $_{1}$ & Average $_{2}$ \\
\hline indep & $90 \%$ & $75 \%$ & $90 \%$ & $75 \%$ & $75 \%$ & $75 \%$ & $80 \%$ & $80 \%$ \\
\cline { 1 - 3 } & 20 & 3 & 3 & 20 & 3 & 3 & 10 & 15 \\
jobllution & $40 \%$ & $10 \%$ & $10 \%$ & $10 \%$ & $40 \%$ & $10 \%$ & $30 \%$ & $20 \%$ \\
\hline rural & $4 \%$ & $1 \%$ & $1 \%$ & $1 \%$ & $1 \%$ & $4 \%$ & $2 \%$ & $3 \%$ \\
\hline WTP/month & 9,5 & 2,1 & 3,7 & 4,1 & 5,1 & 3,0 & 5,7 & 5,6 \\
\hline WTP/year & 114 & 25,8 & 45 & 49 & 61,7 & 35,6 & 69 & 67,1 \\
\hline $\begin{array}{l}\text { Yearly } \\
\begin{array}{l}\text { overest. } \\
\text { (EUR) }\end{array}\end{array}$ & $\mathbf{2 9}$ & $\mathbf{6 , 5}$ & $\mathbf{8 , 9}$ & $\mathbf{1 3 , 2}$ & $\mathbf{1 6 , 7}$ & $\mathbf{9 , 7}$ & $\mathbf{1 7 , 9}$ & $\mathbf{1 7 , 6}$ \\
\hline $\begin{array}{l}\text { Yearly } \\
\text { overest. (\%) }\end{array}$ & $\mathbf{3 4 \%}$ & $\mathbf{3 4 \%}$ & $\mathbf{2 5 \%}$ & $\mathbf{3 7 \%}$ & $\mathbf{3 7 \%}$ & $\mathbf{3 7 \%}$ & $\mathbf{3 5 \%}$ & $\mathbf{3 6 \%}$ \\
\hline
\end{tabular}

The data in Table 6 shows that by not including the SQ option, the same sample of respondents would have been forced express a much higher WTP compared to the one provided in the unforced choice model. The result would have been an overestimation of more than one third of the WTP. By imposing the forced choice, we would have disregarded the economic principle of budgetary constraints - the respondents may not have the necessary funds to opt for a more costly offer or they may 
consider that its cost outweighs its benefits, thus not insuring an adequate compensating variation, as discussed previously.

\section{Conclusions and Implications}

The aim of this paper has been to provide empirical evidence that demonstrates the risks of not including the status quo option in a discrete choice experiment and to demonstrate how it could be easily implemented, reducing or eliminating some of the disadvantages discussed in the existing literature. We implemented a discrete choice experiment on a sample of Romanian households in order to determine their willingness to pay for increased supply of electricity from renewable sources.

Our experimental design was composed of a series of choice sets that included two profiles of societal benefits associated with local renewable energy production (such as national energy independence, reduction of pollution effects and others), as well as one profile of the existing status quo in Romania (with no additional cost). The respondents were asked two questions for each choice set instead of the commonly used one question design. The first question asked which profile they preferred out of the two non-status quo options, implying a forced choice. The second asked which option they would prefer (including the status quo) if they were to sign a new electricity supply contract today.

The proposed method is simple to implement and it does not significantly increase the already complex scales typically used for discrete choice experiments. Even though it generates significant additional information, it does not significantly increase the choice burden on the respondents and does not necessitate adding additional scales to the already elaborate questionnaire. Using this approach, researchers are able to generate two distinct econometric models, one of which does not contain the status quo option. As respondents are first asked to choose between the two experimental profiles, this approach limits any impact of the status quo bias on the non-status quo model.

An additional benefit of this approach is that, during the data analysis, it is possible to perform a detailed analysis regarding status quo bias using the same sample of respondents, with answers collected at the same moment in time. This is arguably a more precise solution than using a split sample approach, as demonstrated by Veldwijk et al. (2014), and it eliminates several external variables that could affect respondents if a testretest approach was used to implement the two choice experiments.

One aspect that could be explored further is the potential contribution of this study to the body of literature that assesses the appearance of status quo bias and the factors that influence this phenomenon. According to observations made by Haaijer et al. (2001), Barreiro-Hurle et al. (2018) and Oehlmann et al. (2017), our study includes several factors that could have generated prevalent status quo bias: using choice sets with only two profiles and a status quo option, high number of choice tasks (16 per respondent), a relatively wide range of attributes and levels ( $4^{5}$ experimental design), proposing a choice between two hypothetical options and a status quo, not accounting for heterogeneity of respondents in the econometric model (we use the conditional multinomial logit model). However, out of the total number of observations, less than $30 \%$ were choices of the status quo, below the level seen in studies where status quo biases were confirmed. 
Our results show that by not including the status quo option it is possible to overestimate willingness to pay for renewable electricity by over one third. Such an error in estimation in the case of using choice experiments to design a pricing strategy would likely generate the failure of a product or service on the market. In the case of a study that seeks to offer guidance for governmental policies in the field of energy, such a large overestimation of willingness to pay could amplify the phenomenon of energy poverty. This, in turn, can lead to large protests and social movements, such as those observed in Bulgaria in 2013, which were the result of electricity price hikes partially caused by green certificate support schemes (Euronews, 2013). In fact, green energy support schemes have been revised downwards across the European Union, one of the key arguments being the desire to limit their impact on electricity prices, as explained by Stoica (2018).

While we believe that the results do support the conclusions, it is worth noting that the W'TP figures illustrated above cannot be extrapolated for the general population of Romania or Iaşi County. The specific limitations of the judgement sampling procedure, as well as the relatively high number of choice tasks per respondent are likely to have had an impact on the resulting WTP estimation.

In conclusion, the discrete choice experiment method demonstrated in this paper can provide a relevant and useful example for future studies regarding the willingness to pay for renewable energy and for correctly valuating other environmental goods and services. We consider that through societal consensus and soft governmental policies based on voluntary contributions designed around correct estimations of consumers' willingness to pay, it is possible to build a truly sustainable future from an economic, ecological, as well as social point of view.

\section{Acknowledgments}

This work was supported by a grant of the Romanian Ministry of Research and Innovation, CNCS-UEFISCDI, project number PN-III-P1-1.1-PD-2016-1864, within PNCDI III.

\section{References}

Ahtiainen, H., Pouta, E., Artell, J. (2015). Modelling asymmetric preferences for water quality in choice experiments with individual-specific status quo alternatives. Water Resources and Economics Vol. 12, $1-13$.

Barreiro-Hurle, J., Espinosa-Godeda, M., Martinez-Paz, J.M. \& Perni, A. (2018). Choosing not to choose: A meta-analysis of status quo effects in environmental valuations using choice experiments. Economia Agraria y Recursos Naturales - Agricultural and Resource Economics 18(1), 79-109: doi.org/10.7201/earn.2018.01.04.

Bonnichsen, O., Ladenburg, J. (2013). Reducing status quo bias in choice experiments. Nordic Journal of Health Economics, Vol. 3, No.1, 47-67: dx.doi.org/10.5617.

Bonnichsen, O., Ladenburg, J., 2010. Reducing Status Quo Bias in Choice Experiments - An Application of a Protest Reduction Entreaty, FOI Working Paper 2010 / 7. Institute of Food and Resource Economics, University of Copenhagen, Copenhaga.

Bouzarovski, S., Petrova, S., \& Sarlamanovb, R. (2012). Energy poverty policies in the EU: A critical perspective. Energy Policy, 49, 76-82. 
Chen, W.Y., Liekens, I., Broekx, S. (2017). Identifying Societal Preferences for River Restoration in Densely Populated Urban Environment Evidence from a Discrete Choice Experiment in Central Brussels. Environmental Management, 60, 263-279: doi 10.1007/s00267-017-0885-5.

Data.gov.ro (2019). Romanian population by age group and sex. Available at: http://data.gov.ro/ on 21.07.2019

Energy Information Administration. (2019). International Energy Statistics. (Available at: https://www.eia.gov/beta/international/data/, on 20.06.2019)

Euronews (2013). Weekend of rage in Bulgaria as tens of thousands protest electricity prices. Available at: http://www.euronews.com/2013/02/18/xyz-weekend-of-rage-in-bulgaria-as-tens-of-thousandsprotest-electricity-prices, on 20.06 .2013

Fiorio, C.V., \& Florio, M. (2013). Electricity prices and public ownership: Evidence from the EU15 over thirty years. Energy Economics, 39, 222-232.

Grabicki, F., Menges, R. (2017). Status quo bias and consumers' willingness to pay for green electricity: A discrete choice experiment with real economic incentives in Spengler, T., Fichtner, W., Geiger, M.J., Rommelfanger, H., Metzger, O. (eds.) Entscheidung-sunterstützung in Theorie und Praxis. Springer Gabler. ISBN: 978-3-658-17579-5. doi: 10.1007/978-3-658-17580-1.

Greenacre, L. (2013). Learning Choice-Based Conjoint \& Discrete Choice Experiments. Available at: https://www.udemy.com/learningcbc/, on 20.06.2019.

Haaijer, R., Kamakura, W., Wedel, M. (2001). The 'no-choice' alternative in conjoint choice experiments. International Journal of Market Research, 43, 93-106.

Holmes, T.P., Adamowicz, W.L. (2003). Attribute-based methods, in: Champ, P.A., Boyle, K.J., Brown, T.C. (Eds.), A Primer on Nonmarket Valuation. Springer Science+ Business Media, New York.

Kaenzig, J., Heinzle, S.L., Wüstenhagen, R. (2013). Whatever the customer wants, the customer gets? Exploring the gap between consumer preferences and default electricity products in Germany. Energy Policy, 53, 311-322.

Louviere, J.J., Hensher, D.A., Swait, D.J. (2000). Stated Choice Models: Analysis and Applications. Cambridge University Press, Cambridge.

Malhotra, N.K., Birks, D.F. (2007) Marketing Research: An applied approach, Third European edition. Pearson Education Limited, Harlow.

Maxim, A. (2015). Relevant attributes of renewable energy development in the case of Romanian households. Procedia Economics and Finance, Vol. 20, 372-382, ISSN: 2212-5671.

Maxim, A., Mihai, C., Apostoaie, C.M., Maxim, A. (2017). Energy Poverty in Southern and Eastern Europe: Peculiar Regional Issues, European Journal of Sustainable Development, Vol. 6, No. 1, 247-260, ISSN: 2239-5938.

Norhidayan, W.M., Wills, S., Powe, N. (2019). The Status Quo in Discrete Choice Experiments: Is it Revelant? The Singapore Economic Review: doi/abs/10.1142/S0217590819500036

Oehlmann, M., Meyerhoff, J., Mariel, A., Weller, P. (2017). Uncovering context-induced status quo effects in choice experiments. Journal of Environmental Economics and Management, 8, 59-73.

Orme, B.K. (2010). Getting Started with Conjoint Analysis: Strategies for Product Design and Pricing Research, Second edition. Research Publishers LLC, Madison

Pedersen, L.B., Gyrd-Hansen, D. (2013). Implications of researchers dubious use of the 'neither' option, and recommendations on the future use of status quo and 'opt out' options in choice experiments, International Choice Modelling Conference, Oulton Hall.

Sandorf, E.D., Aanesen, M., Navrud, S. (2016). Valuing unfamiliar and complex environmental goods: A comparison of valuation workshops and internet panel surveys with videos. Ecological Economics 196, 50-61.

Stoica, A. (2018). ANRE reduces the obligation of green certificates acquisition. Available at: https://energyindustryreview.com/renewables/anre-reduces-the-obligation-of-green-certificatesacquisition/, on 20.06.2013

Tinelli, M., Ryan, M., and Bond, C. (2016). What, who and when? Incorporating a discrete choice experiment into an economic evaluation. Health Economics Review, 6-31: doi 10.1186/s13561-016-0108-4.

Veldwijk, J., Lambooij, M.S., de Bekker-Grob, E.W., Smit, H.A., de Wit, G.A. (2014). The Effect of Including an Opt-Out Option in Discrete Choice Experiments. PLoS ONE Vol. 9. No. 11, 1-9: e111805. ISSN: 1578-0732. doi:10.1371/journal.pone.0111805. 